\title{
W-Band (95 GHz) Radar Attenuation in Tropical Stratiform Ice Anvils
}

\author{
Alain Protat AND SURENDRA RAUNIYAR \\ Australian Bureau of Meteorology, Melbourne, Victoria, Australia \\ JULIEN DELANOË \\ Laboratoire Atmosphère, Milieux, Observations Spatiales, Université Versailles Saint-Quentin, IPSL, CNRS, \\ Sorbonne Université, Guyancourt, France \\ EMMANUEL FONTAINE \\ Department of Atmospheric Sciences, National Taiwan University, Taipei, Taiwan \\ ALFONS SCHWARZENBOECK \\ Laboratoire de Météorologie Physique, Université Blaise Pascal, Clermont-Ferrand, France
}

(Manuscript received 5 September 2018, in final form 24 March 2019)

\begin{abstract}
Attenuation of the $\mathrm{W}$-band $(95 \mathrm{GHz})$ radar signal by atmospheric ice particles has long been neglected in cloud microphysics studies. In this work, $95-\mathrm{GHz}$ airborne multibeam cloud radar observations in tropical stratiform ice anvils are used to estimate vertical profiles of $95-\mathrm{GHz}$ attenuation. Two techniques are developed and compared, using very different assumptions. The first technique examines statistical reflectivity differences between repeated aircraft passes through the same cloud mass at different altitudes. The second technique exploits reflectivity differences between two different pathlengths through the same cloud, using the multibeam capabilities of the cloud radar. Using the first technique, the two-way attenuation coefficient produced by stratiform ice particles ranges between 1 and $1.6 \mathrm{~dB} \mathrm{~km}^{-1}$ for reflectivities between 13 and $18 \mathrm{dBZ}$, with an expected increase of attenuation with reflectivity. Using the second technique, the multibeam results confirm these high attenuation coefficient values and expand the reflectivity range, with typical attenuation coefficient values of up to $3-4 \mathrm{~dB} \mathrm{~km}^{-1}$ for reflectivities of $20 \mathrm{~dB} Z$. The potential impact of attenuation on precipitating-ice-cloud microphysics retrievals is quantified using vertical profiles of the mean and the 99th percentile of ice water content derived from noncorrected and attenuation-corrected reflectivities. A large impact is found on the 99th percentile of ice water content, which increases by $0.3-0.4 \mathrm{~g} \mathrm{~m}^{-3}$ up to $11-\mathrm{km}$ height. Finally, T-matrix calculations of attenuation constrained by measured particle size distributions, ice crystal mass-size, and projected area-size relationships are found to largely underestimate cloud radar attenuation estimates.
\end{abstract}

\section{Introduction}

Millimeter-wave radars (also called "cloud" radars) have become crucial instruments in the field of atmospheric science, because of their unique capacity to detect clouds and precipitation while remaining compact and easy to deploy from ground, aircraft, or satellite platforms, as compared to weather radars. A major limitation of existing cloud radars (mostly developed at Ka band and $\mathrm{W}$ band, corresponding to frequencies of about

Corresponding author: Alain Protat, alain.protat@bom.gov.au
35 and $94 \mathrm{GHz}$, respectively) is the substantial signal attenuation through optically thick liquid clouds and rain (e.g., Lhermitte 1990, 2002; Clothiaux et al. 1995; Li et al. 2001). For instance, using an exponential drop size distribution assumption, Lhermitte (1990) estimated that a $10 \mathrm{~mm} \mathrm{~h}^{-1}$ rainfall produces a one-way attenuation coefficient of $2 \mathrm{~dB} \mathrm{~km}^{-1}$ at $35 \mathrm{GHz}$, and $7 \mathrm{~dB} \mathrm{~km}^{-1}$ at $95 \mathrm{GHz}$.

Reviewing the literature for studies of Ka-band or W-band attenuation in stratiform precipitating ice clouds indicates that this topic has received little attention. It also reveals that attenuation by precipitating ice is often assumed negligible in ice microphysics retrieval techniques 
or flagged as not retrievable [e.g., the CloudSat Radar-Only Cloud Water Content Product (2B-CWC-RO) and Radar-Visible Optical Depth Cloud Water Content Product (2B-CWC-RVOD); Austin et al. 2009; the triple-frequency retrieval from Gaussiat et al. (2003)]. However, recent triple-frequency snow retrievals (e.g., Kneifel et al. 2011; Leinonen et al. 2011, 2012; Kulie et al. 2014; Grecu et al. 2018) and some advanced satellite ice microphysics retrievals using active and passive remote sensing [e.g., Grecu and Olson 2008; the CloudSat Snow Profile Product (2C-SNOW-PROFILE); Wood and L'Ecuyer 2018] now include precipitating-ice attenuation as part of their retrieval framework. These precipitating-ice retrieval developments would benefit from more quantitative studies of precipitating-ice attenuation. Some studies provide estimates of attenuation in snowstorms from actual observations, but only in the form of path-integrated attenuation (i.e., no information on the vertical distribution). Leinonen et al. (2012) and Grecu and Olson (2008) estimated path-integrated attenuation of up to $10 \mathrm{~dB}$ from airborne W-band observations of a midlatitude snowstorm over Wakasa Bay associated with reflectivities ranging from 10 to $20 \mathrm{dBZ}$. Leinonen et al. (2011) estimated maximum W-band attenuations not exceeding $1 \mathrm{~dB} \mathrm{~km}^{-1}$ in snowstorms over Finland. Kneifel et al. (2011) published attenuation values ranging from 0.2 to $1 \mathrm{~dB} \mathrm{~km}^{-1}$ for snow water contents between 0.1 and $0.5 \mathrm{~g} \mathrm{~m}^{-3}$ from scattering calculations using snow aggregates. Kulie et al. (2014) concluded from detailed scattering calculations using snow aggregates that "the exact relationship used to correct W-band observations for attenuation is somewhat arbitrary," as the aggregate density assumption can produce large differences in their scattering calculations of the relationship between W-band attenuation and unattenuated reflectivity. Another main source of uncertainty reported in these observational studies is how much of the total W-band attenuation is caused by supercooled liquid water in these snowstorms. Using cloud-resolving outputs for a lake-effect snowstorm, Grecu and Olson (2008), estimated this fraction to be around $30 \%$ for their case study, but this is assuming that the model realistically represents the microphysical properties of supercooled liquid water. Other studies of convective snow clouds found values ranging from 1 to $4 \mathrm{~dB} \mathrm{~km}^{-1}$ due to embedded supercooled liquid cloud layers (e.g., Matrosov 2009; Kneifel et al. 2011; Kulie et al. 2014). Finally, when using differences between W-band and unattenuated reflectivities at a higher wavelength to characterize precipitating-ice attenuation, the fraction of the reflectivity difference due to non-Rayleigh scattering is a potential source of overestimation of attenuation.
It must be noted that none of these studies were conducted in tropical stratiform precipitation, where the detailed ice microphysical properties and dominant microphysical processes are expected to be different from midlatitude and high-latitude snowstorms. A better understanding and quantification of W-band attenuation in different types of stratiform precipitation is needed to inform further ice microphysics retrieval developments, including for CloudSat and future cloud radar or multifrequency radar missions.

Recent aircraft observations collected with a multibeam 95-GHz Doppler radar (Protat et al. 2009; Delanoë et al. 2013) in the stratiform ice part of West African mesoscale convective systems (MCSs) repeatedly exhibited intriguing features. While the aircraft progressively ascends within the MCS stratiform part, the maximum in radar reflectivity is systematically located close to the aircraft and reflectivity systematically decreases with radar range (Fig. 1). Ice-particle aggregation is the dominant process in stratiform ice precipitation, which should result in an increase in reflectivity from cloud top down to above melting layer, except just above the melting layer where the combination of ice particle aggregation and non-Rayleigh scattering results in a decrease in reflectivity (e.g., the 94-GHz radar "dim band"; Heymsfield et al. 2008). In Fig. 1, reflectivity is found to systematically decrease from the aircraft flight altitude downward, which is not consistent with ice aggregation being the dominant process. The most likely explanation for this feature is attenuation. It must be noted that this feature has been observed time and time again in four recent field experiments focused on tropical stratiform ice parts of MCSs [two experiments in West Africa and the Maldives Island, described in Fontaine et al. (2014) and two "high ice water content" experiments in Darwin, Australia, and Cayenne, French Guiana, described in Strapp et al. (2018) and Dezitter et al. (2013)]. In situ observations for those cases showed that no supercooled liquid water content was present. No graupel or hail was found either from analyses of the two-dimensional (2D) probe images. Therefore, supercooled water, graupel, or hail cannot explain this attenuation signature. From a qualitative analysis of the $2 \mathrm{D}$ probe images, these regions are characterized by ice aggregates (e.g., Bouniol et al. 2010), which, because of their higher density, are intuitively expected to produce more attenuation than pristine crystals or chain-like aggregates commonly observed in the upper part of tropical stratiform anvils (e.g., Stith et al. 2002; Connolly et al. 2005; Gayet et al. 2012).

Since this effect is not negligible, accurate estimates of 95-GHz attenuation in stratiform ice anvils are needed for several applications. The first obvious application is the 


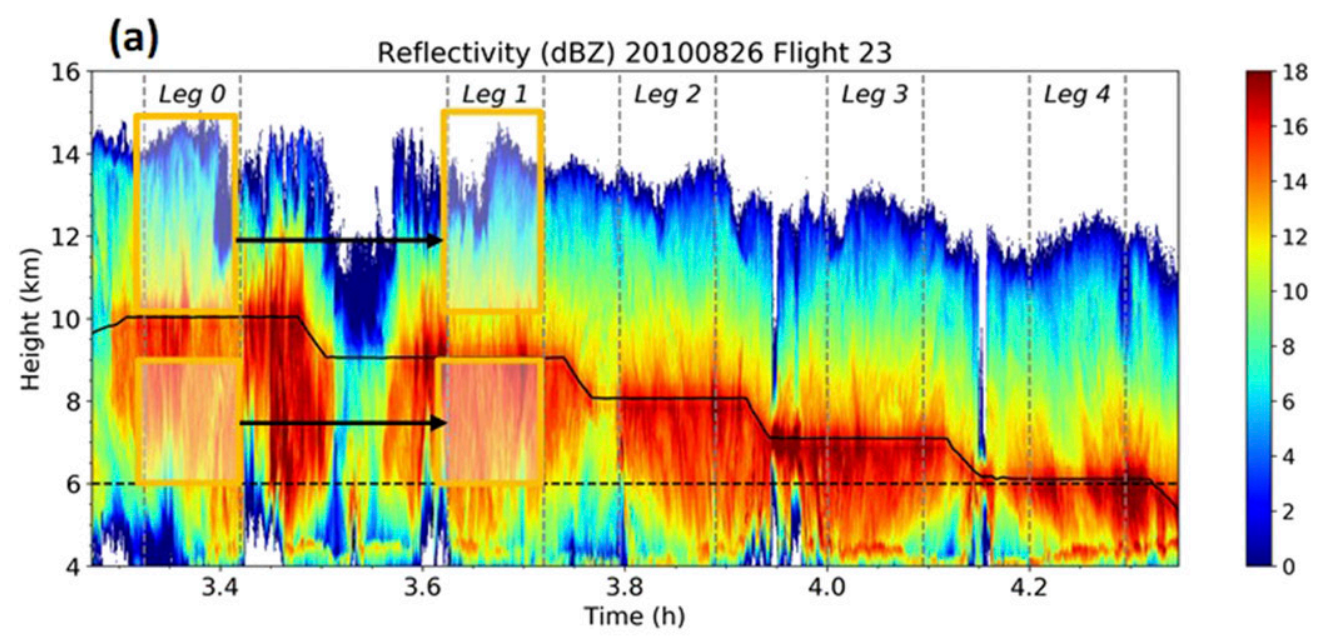

(b) Time difference method

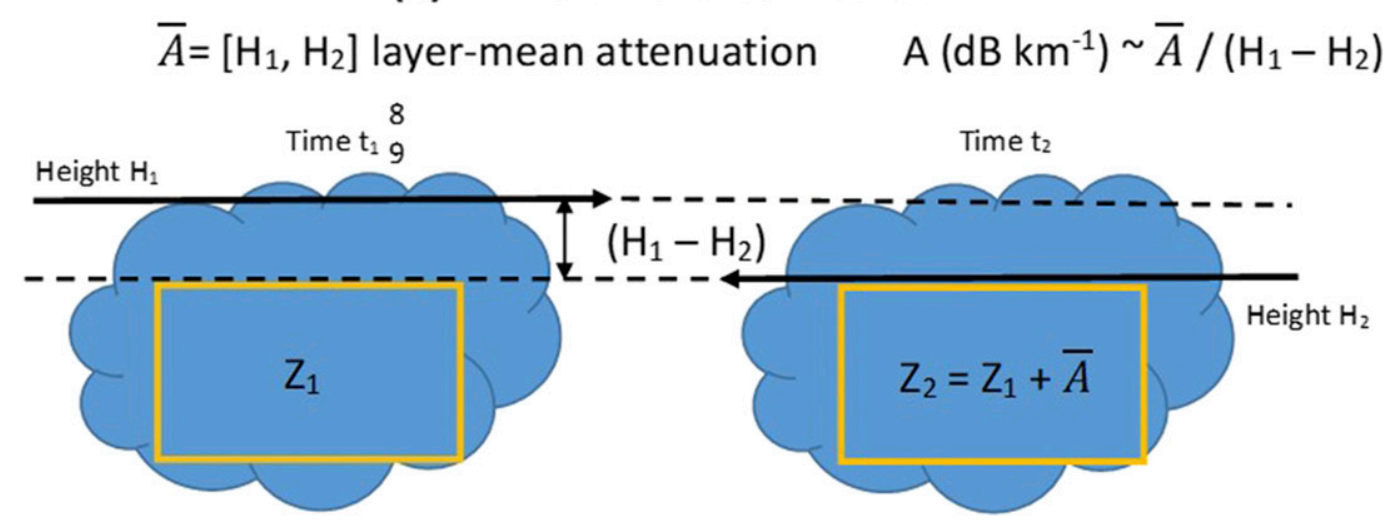

\section{(c) Spatial difference method}

\section{$\bar{A}^{\prime}=$ attenuation due to $\left(\mathrm{r}_{1}-\mathrm{r}_{2}\right) \quad \mathrm{A}\left(\mathrm{dB} \mathrm{km} \mathrm{km}^{-1}\right) \sim \bar{A}^{\prime} /\left(\mathrm{r}_{2}-\mathrm{r}_{1}\right)$}

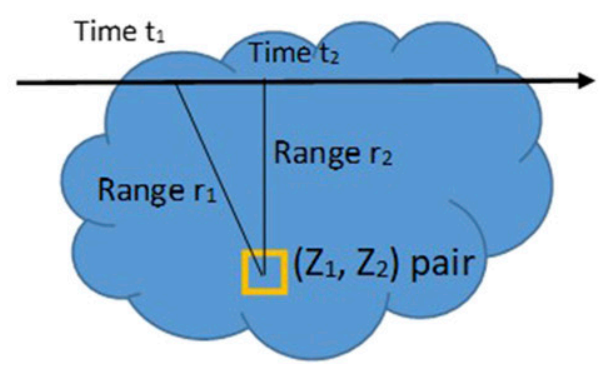

FIG. 1. (a) Vertical cross section of radar reflectivity for $M T$-AFRICA flight 23. The flight track is the solid black line. Vertical dashed lines outline the start and end of each flight pass through the same cloud mass. The four orange rectangles outline the areas used for the reflectivity comparisons and resulting attenuation coefficient estimations using PDF and mean vertical profile comparisons with the time-difference technique. The horizontal dashed line at 6-km height corresponds to the minimum height used in our study. (b),(c) Cartoons explaining the time difference and spatial difference techniques, respectively (see text for details). 
quantitative estimate of stratiform ice cloud microphysical properties from active and passive remote sensing from ground, aircraft, and satellite. The impact of neglecting the effect of $95-\mathrm{GHz}$ attenuation in MCS studies needs to be assessed. For instance, CloudSat $94-\mathrm{GHz}$ radar products have already been extensively used in the literature to characterize different morphology and microphysical growth processes in continental versus oceanic stratiform parts of MCSs (e.g., Cetrone and Houze 2009). Another major application that requires a better knowledge of $95-\mathrm{GHz}$ attenuation is the characterization of ice crystal icing for the aviation industry. A recent focus of aviation authorities has indeed been to characterize the formation and maintenance processes involved in a new form of icing not involving supercooled liquid clouds, named ice crystal icing. In short, ice crystal icing is found to occur within about $50 \mathrm{~km}$ from deep convective cores and corresponds to low to moderate turbulence areas with high concentrations of small ice crystals. The ultimate objective of the aviation authorities is to update the regulations related to ice crystal icing. Aircraft field experiments (Strapp et al. 2018; Dezitter et al. 2013; Protat et al. 2016) have been recently conducted to collect in situ and $95-\mathrm{GHz}$ multibeam cloud radar observations of ice water content in and around deep convective cores to update those regulations. The focus is on estimating the 99th percentile of ice water content (IWC) as a function of spatial averaging scale (Strapp et al. 2018). Attenuation needs to be carefully corrected to mitigate its potential impact on this 99th percentile of IWC.

Our main motivation in this work is to quantify 95- GHz attenuation in tropical stratiform ice anvils. In this paper, we take advantage of dedicated aircraft cloud radar observations collected as part of an aircraft campaign for the preparation of the French-Indian Megha-Tropiques (MT) satellite mission over West Africa (MT-AFRICA) to estimate $95-\mathrm{GHz}$ radar attenuation from multiple passes at different flight altitudes and multibeam cloud radar observations through the same stratiform ice anvils detrained from MCSs. This field experiment, observations, and methodologies used to estimate $95-\mathrm{GHz}$ attenuation are described in section 2. Results are then presented in section 3. Main findings are summarized in section 4 .

\section{Observations and methodology}

Observations used in this study are from an aircraft campaign conducted to inform the development of the passive microwave rainfall algorithms for the $M T$ satellite mission with the French Falcon 20 research aircraft from Service des Avions Français Instrumentés pour la Recherche en Environnement (SAFIRE). During this campaign, MT-AFRICA, the Falcon 20 aircraft was based in Niamey (Niger) during the monsoon season (August 2010). The Falcon 20 was equipped with the multibeam 95-GHz cloud Radar System Airborne (RASTA; Protat et al. 2009; Delanoë et al. 2013) and a suite of state-of-the-art optical array probes [the 2DStereo Probe (2D-S) from Stratton Park Engineering Company (SPEC), Inc., and the Precipitation Imaging Probe (PIP) from Droplet Measurement Technologies (DMT)] to measure the particle size distribution (PSD) over the size range 10-6400 $\mu \mathrm{m}$ [see Fontaine et al. (2014) for further details and postprocessing descriptions]. The unique feature of the RASTA $95-\mathrm{GHz}$ radar is the multibeam antenna system, which consists in successive transmission on three noncolinear downward-looking antennas (nadir, $20^{\circ}$ backward from nadir, and $15^{\circ}$ from nadir toward the right wing), then three noncolinear upward-looking antennas (zenith, $20^{\circ}$ backward from zenith, and $15^{\circ}$ from zenith toward the right wing), allowing for the three-dimensional wind to be retrieved below and above the aircraft flight altitude.

Attenuation due to water vapor and oxygen has been estimated and used to correct our reflectivity measurements using the Liebe et al. (1993) model and the atmospheric profiles collected by in situ probes during takeoff and landing. As expected, these corrections were found to be very small for heights above $6 \mathrm{~km}$, which is the minimum height level used in this study. Although the calibration of RASTA does not impact any of the results obtained in what follows (i.e., differences in reflectivity are used), it is worth noting that the radar has been carefully calibrated using accurate measurements of gains and losses through each radar component, remote fixed targets of known backscatter cross sections, and the $\mathrm{Li}$ et al. (2005) ocean surface backscatter technique (Bouniol et al. 2008). Quantitative comparisons with the CloudSat spaceborne 94-GHz radar also showed that the two instruments agreed to within $1 \mathrm{~dB}$ (Protat et al. 2009).

The antennas have been carefully intercalibrated using collocated data from the closest range (i.e., 240-m range on the vertical antenna), where differential attenuation between the backward and vertical beams is negligible. We also checked that excluding reflectivities greater than $5 \mathrm{dBZ}$ in those comparisons yielded the same calibration differences $(0.25$ and $0.15 \mathrm{~dB}$ for the upward and downward antennas, respectively).

The sampling strategy during these $M T$ experiments was to collect in situ particle size distributions, 2D images of ice particles, and vertical cross sections of cloud radar reflectivity and 3D winds in the stratiform part of tropical MCSs from straight flight legs (which will also be called "passes" in this paper) at different altitudes from about 11-km height down to the melting layer and into the liquid part of the MCS, in height steps of about 
$1 \mathrm{~km}$. The strategy was to follow as much as possible the same cloud mass by letting the aircraft drift with flight altitude winds, then descend by about $1 \mathrm{~km}$ during turns to revisit as much as possible the same cloud mass (see Fig. 1). Although this sampling strategy was merely aimed at process studies and the characterization of the temperature variability of the ice crystal mass-size relationship (Fontaine et al. 2014, 2017) the additional value of this sampling strategy is that it potentially allows for a statistical estimation of radar attenuation within the layer composed between two flight altitudes from the analysis of statistical differences in reflectivity between two successive passes. This first method will be referred to as the "time difference" method.

The principle of the time-difference technique is shown in Fig. $1 b$ for the downward-looking radar antennas. The principle is the same when using the upward-looking radar antennas. Two successive passes over the same portion of the stratiform anvil but at different flight altitudes $H_{1}$ and $H_{2}$ are used (Fig. 1b). If we assume that the temporal evolution of the stratiform cloud between $t_{1}$ and $t_{2}$ is nil everywhere in the orange box (i.e., the cloud is "frozen"), the layer-mean attenuation $\bar{A}$ between $H_{1}$ and $H_{2}$ is equal to the difference $\left(Z_{2}-Z_{1}\right)$ for each reflectivity measurement within the orange box. The more realistic assumption we are making is that time differences between statistical properties of reflectivity within the orange box are predominantly due to the layer-mean attenuation $\bar{A}$. In other words, we neglect the statistical reflectivity difference due to the temporal evolution of the stratiform cloud mass under consideration. In our study, we derive two independent estimates of $\bar{A}$ using two different reflectivity metrics: the 50th percentile of the reflectivity probability distribution function (PDF) and the mean vertical profile of reflectivity (averaging in linear units of $\mathrm{mm}^{6} \mathrm{~m}^{-3}$ then converting back to $\mathrm{dB} Z$ ). The attenuation coefficient $\left(\mathrm{dB} \mathrm{km}^{-1}\right)$, is derived as $\bar{A} /\left(H_{1}-H_{2}\right)$. Also, as can be seen in Fig. 1a, convective updrafts embedded in the stratiform region are often seen piercing through the melting layer (corresponding to high attenuation "wedges," usually below 6-km height). To mitigate their impact on our attenuation estimates, all data below 6-km height (1-1.5 km above the melting layer in this region) are discarded in our analysis.

To qualitatively assess the impact of neglecting the cloud temporal evolution between two successive aircraft passes, we first check that the shape of the PDFs at the two different times are very similar, and also that the shape of the mean radar reflectivity profiles of radar reflectivity at the two different time periods are very similar. We also compare the two independent estimates of $\bar{A}$ obtained below and above the attenuating layer for each pair of aircraft passes. Overall, we expect the temporal evolution assumption to be less satisfied closer to the melting layer than in the upper troposphere, because of the previously discussed intermittent convective updrafts embedded within stratiform regions piercing through the melting layer. These convective updrafts are short lived and may therefore not appear on two successive flight passes (see Fig. 1a). A good agreement between estimates from below and above the attenuating layer therefore implies a minimal impact of temporal evolution on the attenuation estimates. These two qualitycontrol procedures (comparing the shapes of PDFs and vertical profiles, and comparing independent attenuation estimates below and above the attenuating layer) were systematically used to make the decision on retaining or discarding a point, as will be illustrated later.

To investigate the potential relationship between layer-mean attenuation $\bar{A}$ and layer-mean reflectivity, we produce a layer-mean reflectivity by averaging all reflectivities (in linear units of $\mathrm{mm}^{6} \mathrm{~m}^{-3}$ ) at $240-\mathrm{m}$ range below the aircraft from the higher-flight-altitude pass, and at 240-m range above the aircraft from the lower-flight-altitude pass. Using only the first valid range bin of the cloud radar allows for the impact of attenuation to be minimized. Also, once the layer-mean attenuation is estimated, this first-guess layer-mean reflectivity is itself corrected for attenuation over 240-m range to further reduce the impact of attenuation on the layer-mean reflectivity estimate.

The second method used to estimate $95-\mathrm{GHz}$ attenuation, referred to as the "spatial difference" method (Fig. 1c), takes advantage of the unique multibeam system of the RASTA cloud radar. For each radar range bin along the nadir or zenith beams (which we will refer to as the "vertical" beams, although they are never perfectly vertical due aircraft motions of course), we find the closest point from the down-backward and up-backward beams, respectively. These backward beams have traversed a longer path than the vertical ones (Fig. 1c). This additional pathlength $\left(r_{2}-r_{1}\right)$ through the clouds produces an additional attenuation for the backward reflectivities, which can be simply estimated as $\left(Z_{2}-Z_{1}\right) /\left(r_{1}-r_{2}\right)$ $\left(\mathrm{dB} \mathrm{km}^{-1}\right.$, Fig. 1c). An assumption in these calculations is that clouds are sufficiently spatially homogeneous to fully attribute the mean difference in reflectivity and pathlength to attenuation, at least from a statistical standpoint. This assumption is obviously not satisfied for each point, and as a matter of fact, a slightly negative (hence impossible) attenuation coefficient is often 
retrieved with this technique. Statistically though, it seems reasonable to assume that this impact of local spatial variability should cancel out on average, as there is no reason for the spatial variability of clouds to systematically enhance or diminish reflectivity.

Another assumption is that the different radar viewing angles from the two antennas (about $20^{\circ}$ ) do not produce systematic differences in reflectivity. It has been shown for pristine crystals like dendrites and columnar ice crystals that even a small difference in viewing angle of $20^{\circ}$ can produce differences in reflectivity of several decibels (e.g., Matrosov et al. 2012). Fortunately, in mature stratiform anvils like those sampled in our field experiments, these pristine crystals are not the dominant type, nearly spherical aggregates are. Differences between nadir and $20^{\circ}$ off-nadir views obtained at $\mathrm{W}$ band from $\mathrm{T}$-matrix calculations for nearly spherical aggregates (aspect ratios of 0.8) were found to be small (Matrosov et al. 2012, their Fig. 6). This effect does presumably introduce errors in individual estimates of attenuation from our technique, but the statistical impact on our results is expected to be minimal, although as explained above this assumption could partly explain the occasional slightly negative (impossible) attenuation retrievals.

Two additional criteria have been set to optimize the quality of the retrieved attenuation coefficient. First, the distance between collocated points along the beams can sometimes take larger values because of sudden aircraft motions. In those instances, reflectivity differences presumably cannot be attributed to attenuation only. Thus, a maximum distance of $200 \mathrm{~m}$ is imposed. Also, since the difference in range close to the aircraft is very small and is the denominator for the attenuation correction, results were found to be unstable for a range difference smaller than about $150 \mathrm{~m}$. Therefore, a conservative minimum range difference of $200 \mathrm{~m}$ has been set.

The time-difference and spatial-difference methods are based on very different assumptions (neglecting temporal evolution versus neglecting spatial variability). An advantage of the spatial-difference technique over the time-difference technique is that estimates are obtained for a wider range of reflectivities, allowing for a more complete description of the relationship between reflectivity and attenuation coefficient. On another hand each attenuation estimate with the spatial-difference method is derived from only two individual measurements of reflectivity, presumably resulting in larger errors. In the absence of a proper reference to validate our $95-\mathrm{GHz}$ attenuation estimates in stratiform ice, the only element of validation of our results will come from the good agreement between these two vastly different approaches.

\section{Results}

In this section we first discuss and compare the results obtained with the time-difference and spatialdifference attenuation retrieval techniques. Then we examine the statistical impact of the retrieved attenuation levels on the statistical profile of reflectivity in the stratiform anvil of tropical MCSs. Finally, we assess whether well-constrained T-matrix scattering calculations at $95 \mathrm{GHz}$ applied to state-of-the art in situ PSD measurements can be used to estimate $95-\mathrm{GHz}$ attenuation accurately.

\section{a. Attenuation estimates using the time-difference method}

We first examine a typical widespread continental stratiform part of an MCS sampled during $M T$ AFRICA flight 23 on 26 August 2010 (same flight as that presented in Fig. 1). We selected this flight because it was typical of the overall sampling strategy, and it highlights both the potential and limitations of the time-difference technique. As explained in section 2, the "attenuating layer" is the layer located between the two flight altitudes (Fig. 1b). As shown in Fig. 1, five successive passes were flown during flight 23, providing four opportunities to estimate layer-mean attenuation in four different layers of about 1-km thickness each: 6-7-, 7-8-, 8-9-, and 9-10-km heights, roughly. As a brief summary, the principle of the time-difference technique is to calculate differences in the 50th percentile of reflectivity PDF and differences in mean vertical profile of reflectivity calculated from two successive flight passes at different flight levels through the same cloud mass. These calculations provide a total of four estimates of the layer-mean attenuation for each pair of aircraft passes (two above and two below the same attenuating layer). In our analysis, each selected flight pass is of the same length so that statistical comparisons are drawn from a similar number of samples.

Figure 2 shows the "time difference" results using the mean vertical profiles of reflectivity. The mean reflectivity profiles (Fig. 2a) clearly show what is expected from attenuation, with vertical profiles above (below) flight altitude shifting at any given height to higher (lower) reflectivities when the aircraft flies at higher (lower) altitude. The vertical profiles of reflectivity difference, which are equivalent to an attenuation coefficient in decibels per kilometer once 

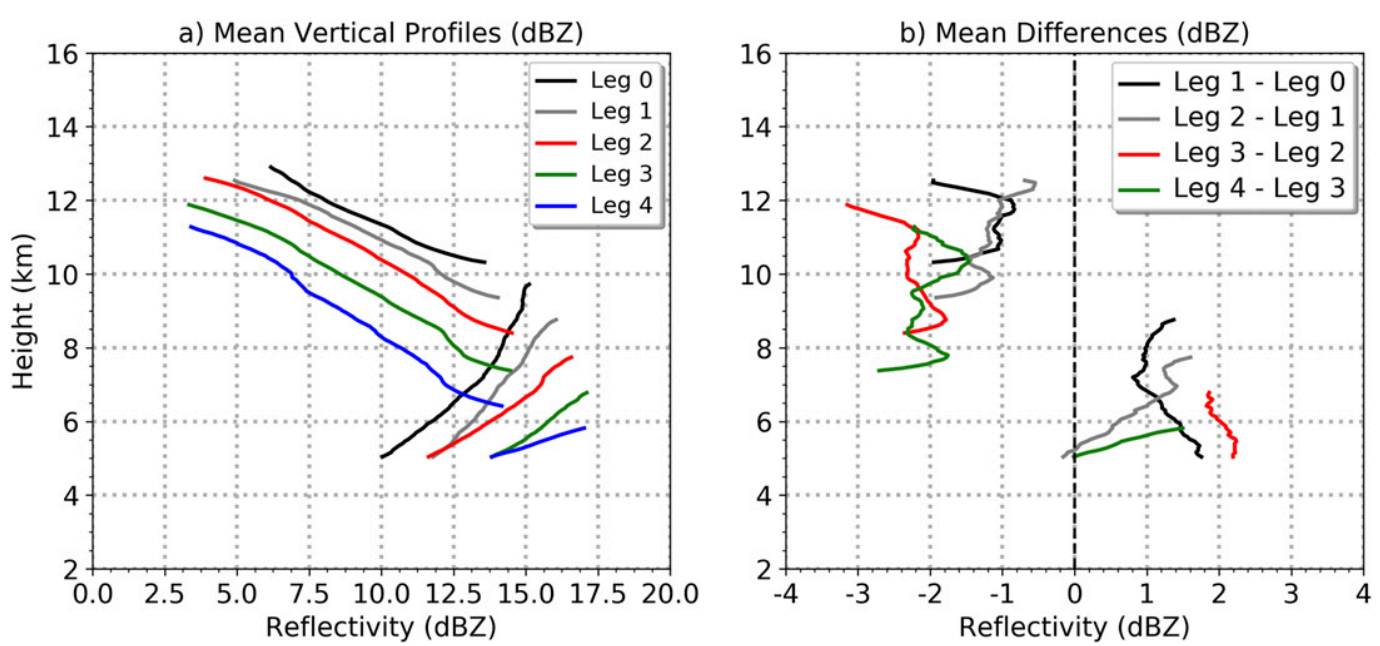

FIG. 2. (a) Vertical profiles of mean radar reflectivity for the five legs defined in Fig. 1. (b) Vertical profiles of reflectivity difference for the four pairs of successive aircraft passes.

normalized per kilometer (Fig. 2b) are not perfectly constant with height, nor perfectly equal below and above the aircraft, as they should be if temporal evolution was fully negligible and the Lagrangian tracking of clouds was perfect. This likely indicates that the number of samples at each height level used to derive the mean vertical profiles of reflectivity is insufficient, which as discussed in section 2 is a downside of using such reflectivity metrics compared to using the reflectivity PDF difference. However, when averaging all individual attenuation estimates from each vertical profile to obtain a single layer-mean attenuation estimate per profile above or below the attenuating layer (Fig. 4), we find a good agreement between attenuation estimates derived from comparisons above and below the attenuating layer (solid black line and solid red line in Fig. 4): 1.1 versus $1.2 \mathrm{~dB} \mathrm{~km}^{-1}$ in the $9-10-\mathrm{km}$ layer, same value of $1.2 \mathrm{~dB} \mathrm{~km}^{-1}$ in the $8-9-\mathrm{km}$ layer, and 1.95 versus $2.25 \mathrm{~dB} \mathrm{~km}^{-1}$ in the 7-8-km layer.

Comparing the PDFs provides additional insights into the impact of temporal evolution and the respective merits of the two reflectivity difference metrics. The PDFs constructed from two successive passes are in excellent agreement overall (Fig. 3). The main exception is between legs 3 and 4 for the $6-7-\mathrm{km}$ attenuating layer (Fig. $3 \mathrm{~g}$ ) where the shapes of the two PDFs clearly differ. Attenuation estimates associated with very different reflectivity PDFs have been discarded by visual inspection when analyzing all the flights. As discussed in section 2, we suggest using the agreement between the attenuation estimates below and above the aircraft, and the agreement between the mean vertical profile and PDF results to quality control the attenuation estimates. Figure 4 clearly shows that the attenuation estimates obtained using differences between the mean vertical profiles and using the difference between the 50th percentiles of the PDFs, both below and above the aircraft, are all in very good agreement. This good agreement is the closest we can get in this study to a validation of the attenuation estimates.

All 11 flights from the $M T$-AFRICA campaign have been processed using the time-difference technique. Twenty-two pairs of suitable flight passes were selected and processed. Out of these 22 pairs, 13 pairs made it through our selection criteria using the similarity of the reflectivity PDFs and the agreement of the attenuation estimates below and above the attenuating layer. Figure 5 shows all retained individual estimates of attenuation coefficient as a function of layer-mean reflectivity. The first thing to note is that the range of layer-mean $95-\mathrm{GHz}$ reflectivities covered by this study is quite narrow, between 13 and $18 \mathrm{dBZ}$. This is most likely due to the focus on stratiform MCS ice anvils. More dedicated aircraft studies are needed to complement this first analysis. Apart from three estimates with values of attenuation coefficient exceeding $2 \mathrm{~dB} \mathrm{~km}^{-1}$, there is a well-defined increase in attenuation coefficient with reflectivity, with values ranging from 1 to about $1.6 \mathrm{~dB} \mathrm{~km}^{-1}$ in the $13-18-\mathrm{dB} Z$ range. The good agreement between independent two-way attenuation estimates from different flights gives credibility to these results. These attenuation coefficient values are not negligible, albeit lower than typical values for rain $\left(\sim 7 \mathrm{~dB} \mathrm{~km}^{-1}\right.$ for a $10 \mathrm{~mm} \mathrm{~h}^{-1}$ rainfall; e.g., Lhermitte 1990), as expected. A closer inspection of the three outliers with higher attenuation 

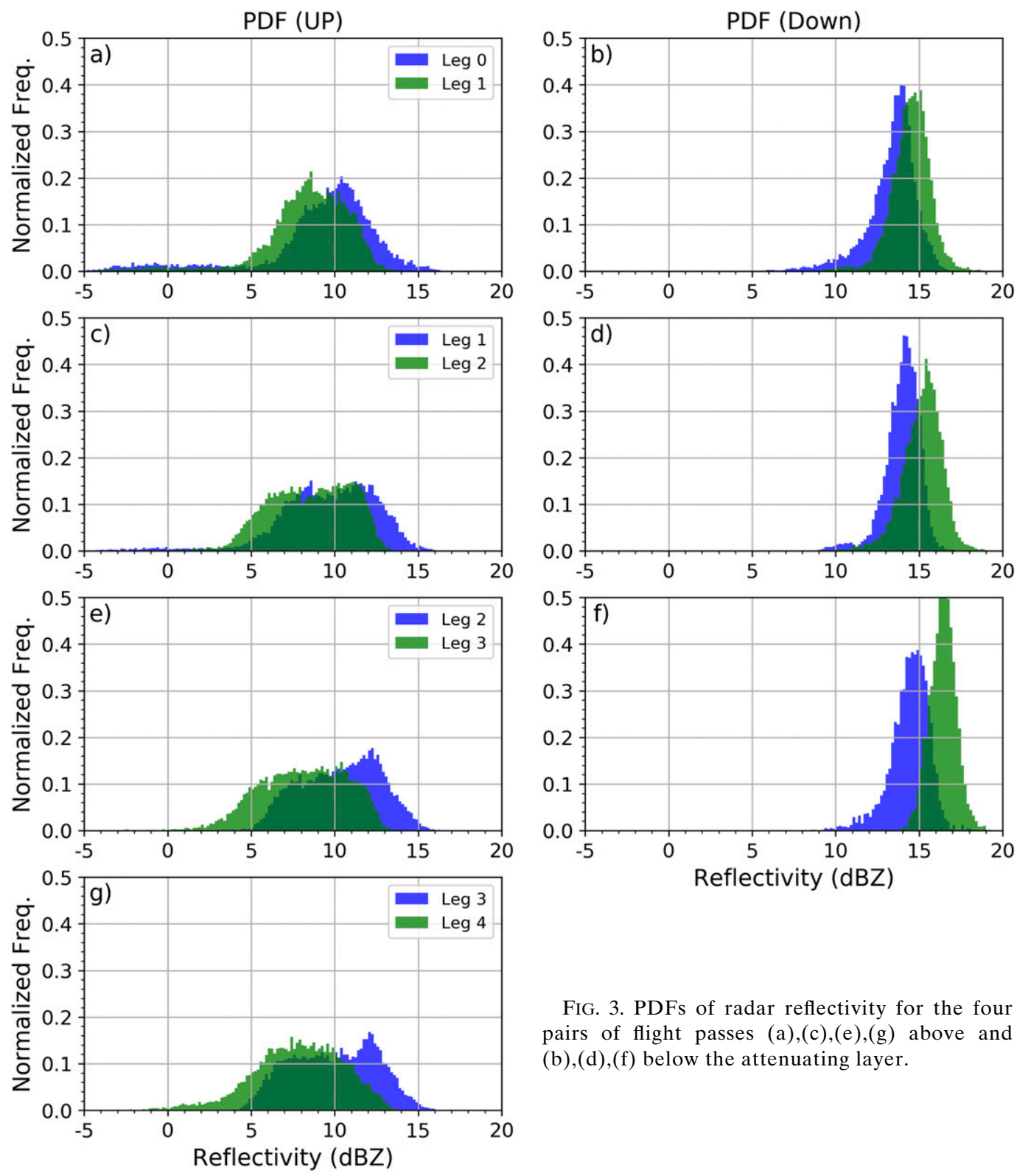

FIG. 3. PDFs of radar reflectivity for the four pairs of flight passes (a),(c),(e),(g) above and (b),(d),(f) below the attenuating layer.

coefficient reveals that the higher attenuation is associated with intermittent convective updrafts exceeding $6 \mathrm{~km}$ in height. The suspicion is that these intermittent convective updrafts produce differences in reflectivities between the two aircraft passes that are not fully due to attenuation. Besides, these convective updrafts likely carry supercooled water above the melting layer, which is expected to produce additional attenuation not due to ice particles. Although the aircraft was equipped with a Rosemount Icing Detector (RICE) to detect supercooled water, the top of these convective updrafts were always below the flight altitude for the three cases. Therefore,

such data cannot be used to confirm the expected presence of supercooled liquid water below flight altitude.

\section{b. Attenuation estimates using the spatial-difference method}

We now turn to an analysis of attenuation estimates obtained with the spatial-difference technique. This technique has been applied to the 11 flights of the $M T$-AFRICA campaign. Radar reflectivities from the vertical antennas have been corrected for attenuation using the multibeam estimates to produce a joint histogram of attenuation-corrected reflectivity 


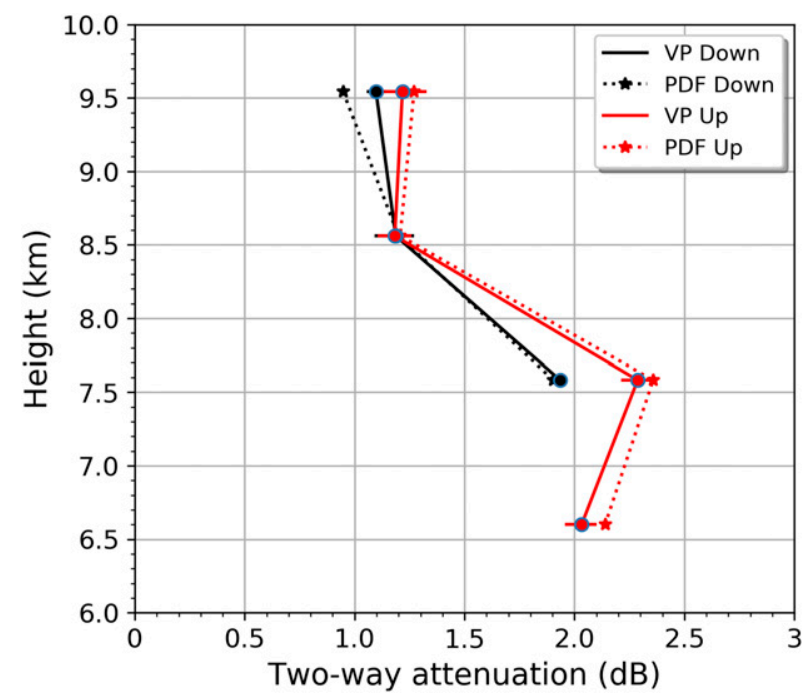

FIG. 4. Layer-mean attenuation estimates for flight 23 as a function of height below (black) and above (red) the attenuating layer using the mean vertical profiles (VP, solid lines) and the PDF comparisons (dotted lines).

versus two-way attenuation coefficient (Fig. 6). As expected, the attenuation coefficient is found to increase with reflectivity. Attenuation is found to be negligible on average for reflectivities below $5 \mathrm{~dB} Z$. The scatter around the most frequent values for each reflectivity bin of the joint histogram is substantial, which confirms that the spatial variability cannot be neglected on a pointby-point basis (as expected). It must be noted that we find that an analysis of individual flights systematically produces a very similar joint reflectivity-attenuation coefficient distribution pattern to that of Fig. 6, with the same amount of scatter (not shown). This suggests that the scatter is indeed due to the technique uncertainties, not to a natural case-to-case variability of the attenuation coefficient-reflectivity relationship. The best linear fit between attenuation coefficient $A\left(\mathrm{~dB} \mathrm{~km}^{-1}\right)$ and reflectivity $Z$ in linear units $\left(\mathrm{mm}^{6} \mathrm{~m}^{-3}\right)$ (reported in Fig. 6 as a dotted line) is

$$
A=0.0325 Z \text {. }
$$

For sake of comparisons with the time-difference approach, the individual estimates from Fig. 5 are superimposed as black circles to the joint distribution of Fig. 6, and a best fit from the limited number of points has also been produced and displayed as a dashed line (the proportionality coefficient is 0.0413 in that case, as reported in Fig. 6). As discussed previously we had only been able to characterize a narrow range of reflectivities with the time-difference approach. However, it is very satisfying to see that

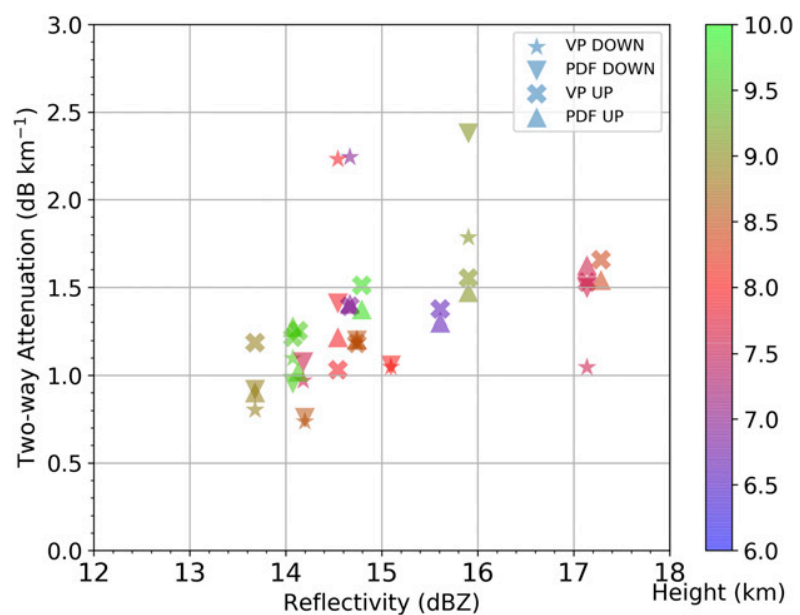

FIG. 5. Estimates of two-way $95-\mathrm{GHz}$ attenuation coefficient as a function of the mean $95-\mathrm{GHz}$ reflectivity of the attenuating layer for all selected pairs of flight passes from the MT-AFRICA experiment.

those points are roughly collocated with the highest frequencies of the joint reflectivity-attenuation coefficient histogram, providing confidence that these different semiquantitative attenuation estimates converge toward very similar levels of attenuation. Given the lack of data points in the 22-25-dBZ range (which is expected, because of non-Rayleigh scattering at $95 \mathrm{GHz}$ limiting the occurrence of reflectivities larger than about $23 \mathrm{dBZ}$ ), we recommend using our attenuationreflectivity relationship only up to reflectivities of about $22 \mathrm{~dB} Z$.

The impact of attenuation correction on the vertical structure of reflectivity in tropical stratiform ice anvils is illustrated in Fig. 7 using MT-AFRICA flight 23 (same as Fig. 1). The attenuation correction is largest for that case below 9-km height, with values of up to about $10 \mathrm{~dB}$ just above the melting layer (Fig. 7c). Once the correction is applied, radar reflectivities are no longer maximum at the aircraft flight altitude location (Fig. 7b) and increase from the aircraft altitude down to the melting layer, which is consistent with ice aggregation being the dominant process in stratiform ice anvils.

\section{c. Impact of attenuation on ice water content statistics in stratiform ice anvils}

An important question arising from these results is the potential impact of neglecting this high attenuation on statistical properties of tropical stratiform ice anvils in past studies using cloud radar observations. As also discussed in the introduction to this work, the aviation industry requires the characterization of the 99th percentile of IWC in and around tropical convective cores 


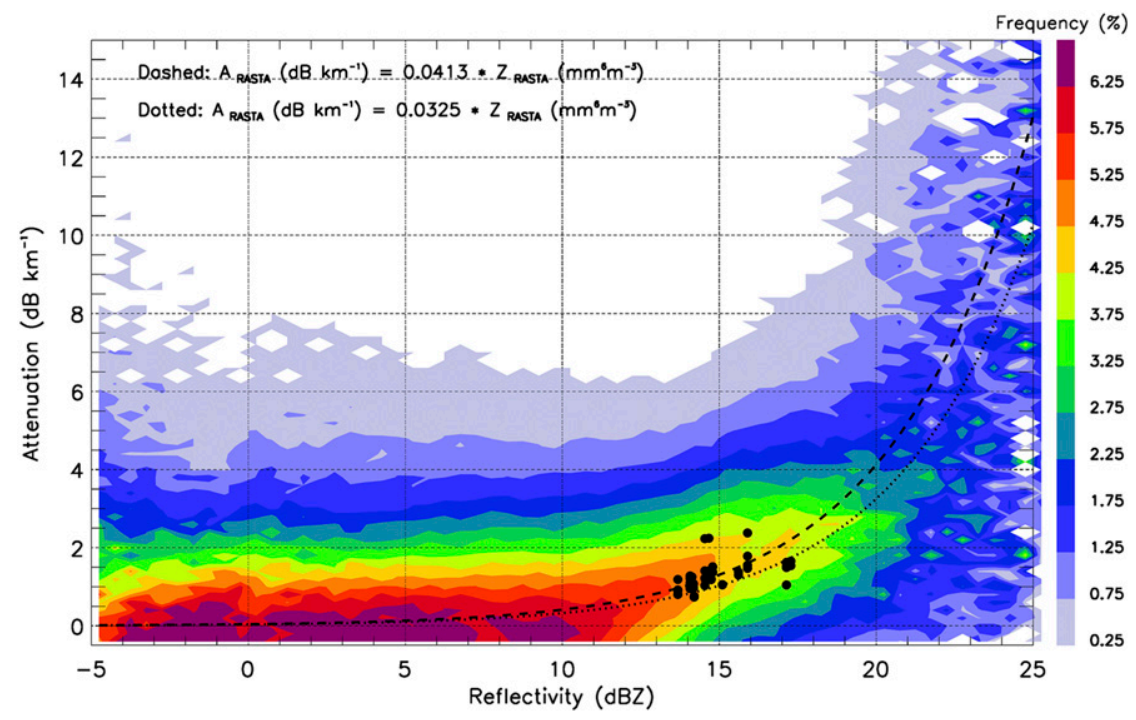

FIG. 6. Joint 95-GHz reflectivity-two-way attenuation coefficient histogram derived using all airborne cloud radar data from the $M T$-AFRICA experiment. The joint histogram has been normalized so that the sum of frequencies is 1 in each reflectivity bin. Black circles are individual estimates from Fig. 5. The dashed line is a fit of the individual points from Fig. 5, while the dotted line is a fit to the joint reflectivity-attenuation coefficient histogram.

to update civil aviation regulations related to ice crystal icing (e.g., Strapp et al. 2018; Dezitter et al. 2013). To provide insights into this impact of attenuation on IWC, the attenuation-reflectivity relationship in (1) has been applied to the whole MT-AFRICA reflectivity dataset, and the attenuated and attenuationcorrected reflectivities have then been converted to IWC using the Protat et al. (2016) IWC- $Z$ relationship [their relation (1)]. From these IWC estimates, the vertical profiles of the mean (black) and the 99th percentile (blue) of the IWC distribution have been derived and are displayed in Fig. 8b. Statistically, the mean reflectivity profile is increased by about $1 \mathrm{~dB}$ because of the attenuation correction, slightly less above $10-\mathrm{km}$ height (Fig. 8a). The corresponding impact on the mean profile of IWC (difference between dashed and solid black lines in Fig. 8b) is about $0.1 \mathrm{~g} \mathrm{~m}^{-3}$, which corresponds to a $12 \%-20 \%$ increase in IWC over the profiles depending on height. The largest impact is clearly on the 99th percentile of IWC, which increases by $0.3-0.4 \mathrm{~g} \mathrm{~m}^{-3}$ up to $11-\mathrm{km}$ height (a $15 \%-25 \%$ increase depending on height), and about $0.1 \mathrm{~g} \mathrm{~m}^{-3}$ above $11-\mathrm{km}$ height. These statistical biases due to attenuation are not negligible and need to be corrected when possible. However, it is important to note that they are within the typical uncertainties of radar IWC retrievals (e.g., Heymsfield et al. 2008; Protat et al. 2016), which implies that conclusions drawn from earlier statistical studies using radar-derived microphysics of tropical convective clouds without $95-\mathrm{GHz}$ ice attenuation should still largely be considered valid.

\section{d. How well do T-matrix calculations approximate attenuation in stratiform ice anvils?}

The final objective of this study is to use our radar estimates of $95-\mathrm{GHz}$ attenuation to examine whether two-way attenuation can be accurately estimated from in situ $2 \mathrm{D}$ probe particle size distribution observations. To do so, T-matrix calculations (Mishchenko et al. 1996) of 95-GHz radar reflectivity and two-way attenuation coefficient have been carried out using the in situ measured PSDs $N\left(D_{\max }\right)$, the measured ice crystal projected area-maximum dimension relationship $A\left(D_{\max }\right)$, and the retrieved crystal mass-maximum dimension relationship $m\left(D_{\max }\right)$ from $M T$-AFRICA. The principle of these "constrained" T-matrix calculations is described in detail in Fontaine et al. (2014). In short, to model the scattering properties of the ice particles using the T-matrix approach, the ice particles are assumed to be oblate spheroids with a flattening equal to the mean aspect ratio of the ice particles with $55 \mu \mathrm{m}<D_{\max }<2 \mathrm{~mm}$. The dielectric properties of ice particles are constrained by the fraction of ice in each hydrometeor [see Eq. (10) in Fontaine et al. (2014)]. The terms $N\left(D_{\max }\right)$ and $A\left(D_{\max }\right)$ are used to estimate the mean aspect ratio of the ice crystals (every $5 \mathrm{~s}$ ), which is introduced as the oblateness of the oblate spheroids in the T-matrix calculations. The $m\left(D_{\max }\right)$ relationship is used to constrain the fraction of ice as a 

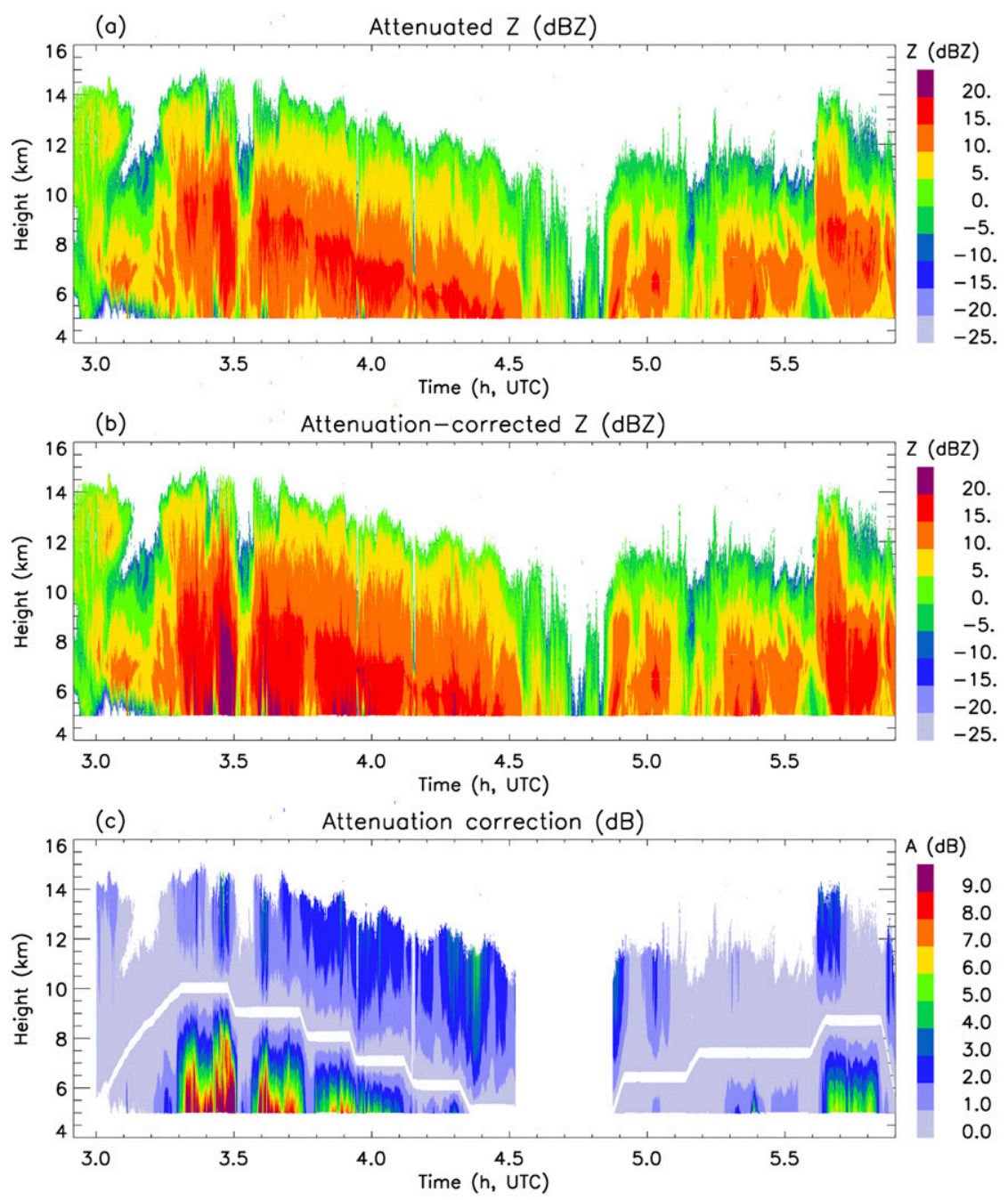

FIG. 7. For $M T$-AFRICA flight 23 (same flight as in Fig. 1), vertical cross sections of (a) attenuated radar reflectivity, (b) attenuation-corrected reflectivity, and (c) attenuation correction using Eq. (1).

function of $D_{\max }$, which is in turn used to calculate the refractive index of the mixture [Garnett 1904; Eq. (1) in Ryzhkov et al. 2011] in the T-matrix calculations. Comparisons of T-matrix simulations and direct 95-GHz reflectivity near flight altitude with RASTA were used to validate these calculations (Fontaine et al. 2014). Figure 9 shows all 5-s T-matrix estimates of two-way attenuation and $95-\mathrm{GHz}$ reflectivity using PSD measurements from the $M T$-AFRICA experiment. Radar estimates from Fig. 5 are also superimposed (black circles) for sake of comparisons. A fit has also been derived for the two sets of points. The spread of T-matrix attenuation coefficient values for any given reflectivity is about $\pm 0.25 \mathrm{~dB} \mathrm{~km}^{-1}$ around the best fit (solid black line). Overall, the T-matrix estimates are about a factor 1.5-2 lower than the cloud radar estimates over the $13-18-\mathrm{dB} Z$ range, although the largest 5 -s T-matrix estimates do overlap with the cloud radar mean attenuation points. Reasons for this discrepancy will need to be explored in the future. Our speculation is that constraining the oblateness of all spheroids in T-matrix calculations with a single mean aspect ratio may result in underestimated attenuation coefficient for a given reflectivity, because of attenuation being more sensitive to smaller particles than reflectivity. So, while reflectivities were in excellent agreement with measured ones on Fontaine et al. (2014), it appears that the current mean aspect ratio approach might not be optimal for attenuation estimation. Refining these T-matrix calculations to better match the range of radar-derived values will be the subject of future research. 

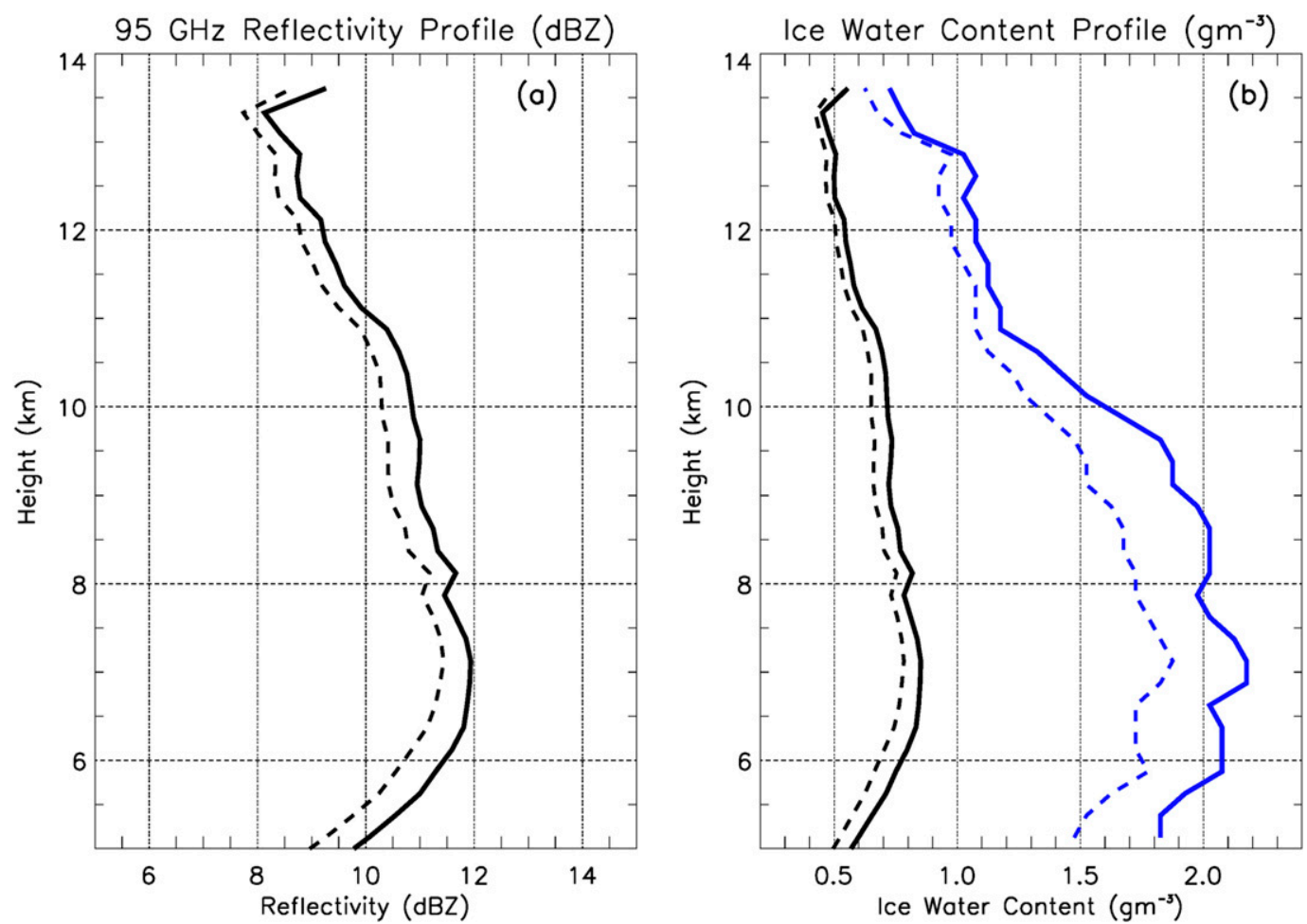

FIG. 8. Vertical profiles of (a) uncorrected (dashed) and attenuation-corrected (solid) mean 95-GHz reflectivity and (b) uncorrected (dashed) and attenuation-corrected (solid) mean IWC (black) and 99th percentile of IWC (blue).

\section{Conclusions}

In this study, we have used unique $95-\mathrm{GHz}$ airborne cloud radar observations in stratiform ice anvils detrained from deep mesoscale convective systems to estimate $95-\mathrm{GHz}$ attenuation produced by ice particles in precipitating-stratiform ice anvils. Two different approaches have been developed and compared. The first technique examined statistical reflectivity differences between repeated passes through the same cloud mass at different altitudes. To mitigate the impact of temporal evolution of clouds between two passes, we compared the functional form of the PDFs and shape of the mean vertical profile of radar reflectivity, below and above the attenuating layer, to select valid points. We found with this first approach that the two-way attenuation coefficient increased from about 1 to $1.6 \mathrm{~dB} \mathrm{~km}^{-1}$ for values of $95-\mathrm{GHz}$ reflectivities ranging between 13 and $18 \mathrm{dBZ}$. Individual estimates for pairs of passes even exceeded $2 \mathrm{~dB} \mathrm{~km}^{-1}$. These values are not negligible when integrated along cloud paths and need to be corrected for in cloud radar retrievals of cloud microphysical properties.

The second technique examined reflectivity differences between two different pathlengths through the same cloud, using multibeam observations from the airborne cloud radar. These multibeam estimates were used to produce a joint histogram of reflectivity versus two-way attenuation coefficient. As expected, the attenuation coefficient is found to increase with reflectivity, from negligible for reflectivities below $5 \mathrm{dBZ}$ to $3-4 \mathrm{~dB} \mathrm{~km}^{-1}$ for $20-\mathrm{dB} Z$ reflectivity. A fit to our retrievals has been proposed for other researchers to correct their datasets for attenuation. Importantly, comparisons with the time-difference approach clearly showed that these two very different techniques, based on very different assumptions, were converging toward similar levels of attenuation for a given reflectivity, with the individual points from the time-difference approach collocated with the highest frequencies of the joint reflectivity-attenuation coefficient histogram derived from the spatial-difference technique.

The potential impact of these high levels of attenuation on cloud microphysics retrievals has been investigated by comparing vertical profiles of the mean and the 99th percentile of ice water content derived from attenuated and attenuation-corrected reflectivities. The impact on the mean profile of IWC was of about $0.1 \mathrm{~g} \mathrm{~m}^{-3}$, which corresponds to a $12 \%-20 \%$ increase in IWC. The largest impact was found on the 99th percentile of IWC, with increases of about $0.3-0.4 \mathrm{~g} \mathrm{~m}^{-3}$ up to $11-\mathrm{km}$ height, and 


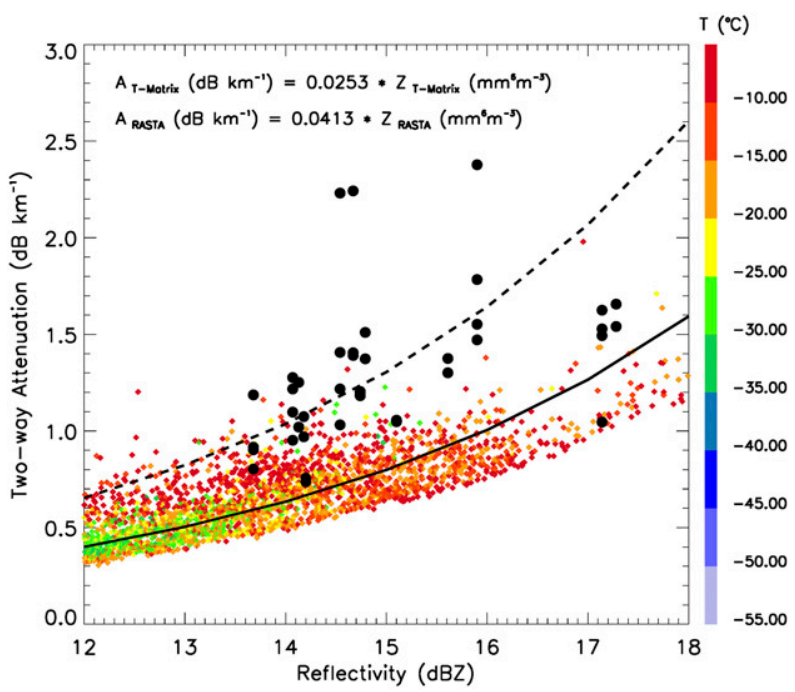

FIG. 9. T-matrix estimates of two-way $95-\mathrm{GHz}$ attenuation coefficient and 95-GHz reflectivity derived from all 5-s PSDs from $M T$-AFRICA (color is flight-level air temperature). All attenuation coefficient estimates from Fig. 5 are also shown as black circles for comparison. The solid black line is a fit to the T-matrix estimates. The dashed black line is a fit to the cloud radar estimates (black circles).

about $0.1 \mathrm{~g} \mathrm{~m}^{-3}$ above $11-\mathrm{km}$ height. These statistical biases due to attenuation are not negligible but are within the typical uncertainties of radar IWC retrievals. This result implies that conclusions drawn from earlier statistical studies using radar-derived microphysics of tropical convective clouds without $95-\mathrm{GHz}$ ice attenuation should still largely be considered valid.

Finally, using measured particle size distributions and retrievals of the relationship between mass-ice crystal size and projected area-ice crystal size at flight altitude, we found that T-matrix calculations of two-way attenuation underestimated our cloud radar estimates by a factor of 1.5-2. Reasons for this will need to be investigated further by conducting sensitivity analysis of scattering calculations to spheroid oblateness assumptions at different particle sizes.

Acknowledgments. This research has received funding from the Federal Aviation Administration (FAA), Aviation Research Division, and Aviation Weather Division, under Agreement CON-I-2901 with the Australian Bureau of Meteorology. The research was also conducted as part of the European Union's Seventh Framework Program in research, technological development, and demonstration under Grant Agreement ACP2-GA-2012-314314 and the European Aviation Safety Agency (EASA) Research Program under Service Contract EASA.2013.FC27. Thanks to the Centre National d'Etudes Spatiales (CNES; French space agency) for funding the Megha-Tropiques validation campaigns and the Service des Avions Français Instrumentés pour la Recherche en Environnement (SAFIRE) for operating the Falcon 20 research aircraft.

\section{REFERENCES}

Austin, R., A. J. Heymsfield, and G. L. Stephens, 2009: Retrieval of ice cloud microphysical parameters using the CloudSat millimeter-wave radar and temperature. J. Geophys. Res., 114, D00A23, https://doi.org/10.1029/2008JD010049.

Bouniol, D., A. Protat, A. Plana-Fattori, M. Giraud, J.-P. Vinson, and N. Grand, 2008: Comparison of airborne and spaceborne 95-GHz radar reflectivity and evaluation of multiple scattering effects in spaceborne measurements. J. Atmos. Oceanic Technol., 25, 1983-1995, https://doi.org/10.1175/2008JTECHA1011.1.

_ J. Delanoë, C. Duroure, A. Protat, V. Giraud, and G. Penide, 2010: The microphysical characterisation of West African mesoscale convective anvils. Quart. J. Roy. Meteor. Soc., 136, 323-344, https://doi.org/10.1002/qj.557.

Cetrone, J., and R. A. Houze Jr., 2009: Anvil clouds of tropical mesoscale convective systems in monsoon regions. Quart. J. Roy. Meteor. Soc., 135, 305-317, https://doi.org/10.1002/qj.389.

Clothiaux, E. E., M. A. Miller, B. A. Albrecht, T. P. Ackerman, J. Verlinde, D. M. Babb, R. M. Peters, and W. J. Syrett, 1995: An evaluation of a $94-\mathrm{GHz}$ radar for remote sensing of cloud properties. J. Atmos. Oceanic Technol., 12, 201-229, https:// doi.org/10.1175/1520-0426(1995)012<0201:AEOAGR > 2.0.CO;2.

Connolly, P. J., C. P. R. Saunders, M. W. Gallagher, K. N. Bower, M. J. Flynn, T. W. Choularton, J. Whiteway, and R. P. Lawson, 2005: Aircraft observations of the influence of electric fields on the aggregation of ice crystals. Quart. J. Roy. Meteor. Soc., 131, 1695-1712, https://doi.org/10.1256/qj.03.217.

Delanoë, J., A. Protat, O. Jourdan, J. Pelon, M. Papazzoni, R. Dupuy, J.-F. Gayet, and C. Jouan, 2013: Retrieval of polar ice cloud properties using RALI platform during POLARCAT campaign. J. Atmos. Oceanic Technol., 30, 57-73, https://doi.org/10.1175/JTECH-D-11-00200.1.

Dezitter, F., A. Grandin, J. L. Brenguier, F. Hervy, H. Schlager, P. Villedieu, and G. Zalamansky, 2013: HAIC-High altitude ice crystals. Proc. Fifth Atmospheric and Space Environments Conf., San Diego, CA, American Institute of Aeronautics and Astronautics, 2674, https://doi.org/10.2514/6.2013-2674.

Fontaine, E., A. Schwarzenboeck, J. Delanoë, W. Wobrock, D. Leroy, R. Dupuy, C. Gourbeyre, and A. Protat, 2014: Constraining mass-diameter relations from hydrometeor images and cloud radar reflectivities in tropical and oceanic convection. Atmos. Chem. Phys., 14, 11367-11392, https:// doi.org/10.5194/acp-14-11367-2014.

, and Coauthors, 2017: Evaluation of radar reflectivity factor simulations of ice crystal populations from in situ observations for the retrieval of condensed water content in tropical mesoscale convective systems. Atmos. Meas. Tech., 10, 2239-2252, https://doi.org/10.5194/amt-10-2239-2017.

Gaussiat, N., H. Sauvageot, and A. J. Illingworth, 2003: Cloud liquid water and ice content retrieval by multiwavelength radar. J. Atmos. Oceanic Technol., 20,1264-1275, https://doi.org/ 10.1175/1520-0426(2003)020<1264:CLWAIC $>2.0 . C O ; 2$.

Gayet, J.-F., and Coauthors, 2012: On the observation of unusual high concentration of small chain-like aggregate ice crystals and large ice water contents near the top of a deep convective 
cloud during the CIRCLE-2 experiment. Atmos. Chem. Phys., 12, 727-744, https://doi.org/10.5194/acp-12-727-2012.

Grecu, M., and W. S. Olson, 2008: Precipitating snow retrievals from combined airborne cloud radar and millimeterwave radiometer observations. J. Appl. Meteor. Climatol., 47, 1634-1650, https://doi.org/10.1175/2007JAMC1728.1.

—, L. Tian, G. M. Heymsfield, A. Tokay, W. S. Olson, A. J. Heymsfield, and A. Bansemer, 2018: Nonparametric methodology to estimate precipitating ice from multiple-frequency radar reflectivity observations. J. Appl. Meteor. Climatol., 57, 2605-2622, https://doi.org/10.1175/JAMC-D-18-0036.1.

Heymsfield, A. J., A. Bansemer, S. Matrosov, and L. Tian, 2008: The 94-GHz radar dim band: Relevance to ice cloud properties and CloudSat. Geophys. Res. Lett., 35, L03802, https://doi.org/ 10.1029/2007GL031361.

Kneifel, S., M. S. Kulie, and R. Bennartz, 2011: A triple frequency approach to retrieve microphysical snowfall parameters. J. Geophys. Res., 116, D11203, https://doi.org/ 10.1029/2010JD015430.

Kulie, M. S., M. J. Hiley, R. Bennartz, S. Kneifel, and S. Tanelli, 2014: Triple-frequency radar reflectivity signatures of snow: Observations and comparisons with theoretical ice particle scattering models. J. Appl. Meteor. Climatol., 53, 1080-1098, https://doi.org/10.1175/JAMC-D-13-066.1.

Leinonen, J., D. Moisseev, V. Chandrasekar, and J. Koskinen, 2011: Mapping radar reflectivity values of snowfall between frequency bands. IEEE Trans. Geosci. Remote Sens., 49, 30473058, https://doi.org/10.1109/TGRS.2011.2117432.

- S. Kneifel, D. Moisseev, J. Tyynela, S. Tanelli, and T. Nousiainen, 2012: Evidence of nonspheroidal behavior in millimeter-wavelength radar observations of snowfall. J. Geophys. Res., 117, D18205, https://doi.org/10.1029/ 2012JD017680.

Lhermitte, R., 1990: Attenuation and scattering of millimeter wavelength radiation by clouds and precipitation. J. Atmos. Oceanic Technol., 7, 464-479, https://doi.org/ 10.1175/1520-0426(1990)007<0464:AASOMW>2.0.CO;2.

- 2002: Centimeter and Millimeter Wavelength Radars in Meteorology. Lhermitte, $550 \mathrm{pp}$.

Li, L., and Coauthors, 2001: Retrieval of atmospheric attenuation using combined ground-based and airborne $95-\mathrm{GHz}$ cloud radar measurements. J. Atmos. Oceanic Technol., 18, 1345-1353, https://doi.org/10.1175/1520-0426(2001)018<1345: ROAAUC $>2.0 . \mathrm{CO} ; 2$.

, G. M. Heymsfield, L. Tian, and P. E. Racette, 2005: Measurements of ocean surface backscattering using an airborne 95-GHz cloud radar-Implication for calibration of airborne and spaceborne W-band radars. J. Atmos. Oceanic Technol., 22, 1033-1045, https://doi.org/10.1175/JTECH1722.1.
Liebe, H. J., G. A. Hufford, and M. G. Cotton, 1993: Propagation modeling of moist air and suspended water/ice particles below 1000 GHz. Preprints, Electromagnetic Wave Propagation Panel Symp., Palma de Mallorca, Spain, Advisory Group for Aerospace Research and Development, 3.1-3.10.

Matrosov, S., 2009: A method to estimate vertically integrated amounts of cloud ice and liquid mean rain rate in stratiform precipitation from radar and ancillary data. J. Appl. Meteor. Climatol., 48, 1398-1410, https://doi.org/10.1175/ 2009JAMC2106.1.

_- G. Mace, R. Marchand, M. Shupe, A. Hallar, and I. McCubbin, 2012: Observations of ice crystal habits with a scanning polarimetric W-band radar at slant linear depolarization ratio mode. J. Atmos. Oceanic Technol., 29, 989-1008, https://doi.org/10.1175/JTECH-D-11-00131.1.

Garnett, J. C. M., 1904: Colours in metal glasses and in metallic films. Philos. Trans. Roy. Soc., 203A, 385-420, https://doi.org/ 10.1098/rsta.1904.0024.

Mishchenko, M. I., L. D. Travis, and D. W. Mackowski, 1996: T-matrix computations of light scattering by nonspherical particles: A review. J. Quant. Spectrosc. Radiat. Transfer, 55, 535-575, https://doi.org/10.1016/0022-4073(96)00002-7.

Protat, A., and Coauthors, 2009: Assessment of CloudSat reflectivity measurements and ice cloud properties using ground-based and airborne cloud radar observations. J. Atmos. Oceanic Technol., 26, 1717-1741, https://doi.org/10.1175/ 2009JTECHA1246.1.

—_, and Coauthors, 2016: The measured relationship between ice water content and cloud radar reflectivity in tropical convective clouds. J. Appl. Meteor. Climatol., 55, 1707-1729, https:// doi.org/10.1175/JAMC-D-15-0248.1.

Ryzhkov, A., M. Pinsky, A. Pokrovsky, and A. Khain, 2011: Polarimetric radar observation operator for a cloud model with spectral microphysics. J. Appl. Meteor. Climatol., 50, 873-894, https://doi.org/10.1175/2010JAMC2363.1.

Stith, J. L., J. Dye, A. Bansemer, A. J. Heymsfield, C. A. Grainger, W. A. Petersen, and R. Ciffelli, 2002: Microphysical observations of tropical clouds. J. Appl. Meteor., 41, 97-117, https://doi.org/ 10.1175/1520-0450(2002)041<0097:MOOTC >2.0.CO;2.

Strapp, J. W., and Coauthors, 2018: An assessment of cloud total water content and particle size from flight test campaign measurements in high ice water content, mixed phase/ice crystal icing conditions: Primary in-situ measurements. Federal Aviation Administration Rep. DOT/FAA/TC-18/1, 243 pp.

Wood, N. B., and T. S. L'Ecuyer, 2018: Level 2C snow profile process description and interface control document: Product version P1 R05. NASA JPL Doc., 26 pp., http:// www.cloudsat.cira.colostate.edu/sites/default/files/products/ files/2C-SNOW-PROFILE_PDICD.P1_R05.rev0_.pdf. 